\title{
ELECTRONIC PROPERTIES OF MOLYBDENUM-IRON-SULFUR-CLUSTERS : APPROACHES TO THE MOLYBDENUM SITE IN NITROGENASE
}

\author{
R.B. Frankel ${ }^{+}$, T.E. Wolff, P.P. Power and R.H. Holm \\ + Francis Bitter National Magnet Laboratory; MTT, Cambridge, MA-02139. \\ Department of Chemistry, Stanford University, Stanford, CA-94305.
}

Nitrogenase consists of two proteins: an iron containing protein and an iron and molybdenum (FeMo) containing protein $[1,2]$, Recent analyses $[3]$ of Mo EXAFS data of the FeMo protein and the FeMo cofactor [4] isolated from it have led to the conclusion that the Mo atom is primarily coordinated to sulfur and is separated by < 3 from another metal atom, not Mo and,therefore, $\mathrm{Fe}$, and that the Mo coordination in native proteins is similar or identical to that in the FeMo cofactor. Together with the known presence of inorganic sulfide and cysteinyl residues in FeMo proteins, it is probable that the active site consists of a Mo-Fe-S(R) polynuclear cluster with metal bridging by sulfide. Using a reaction system consisting of $\mathrm{FeCl}_{3} /\left(\mathrm{R}_{4} \mathrm{~N}\right)_{2} \mathrm{M} \mathrm{S}_{4} / \mathrm{R}^{\mathrm{S} S \mathrm{H}}$ in alcohol solvents, a series of "double cubane" complexes(I) $\left[\mathrm{M}_{2} \mathrm{Fe}_{6} \mathrm{Sg}_{9}(\mathrm{SEt})_{8}\right]^{3-}$, (II) $\left[\mathrm{Mo}_{2} \mathrm{Fe}_{6} \mathrm{~S}_{8}(\mathrm{SEt})_{9}\right]^{3-}$, (III) $\left[\mathrm{M}_{2} \mathrm{Fe}_{7} \mathrm{~S}_{8}(\mathrm{SEt})_{12}\right]^{3-}$ and (IV) $\left[\mathrm{M}_{2} \mathrm{Fe}_{7} \mathrm{~S}_{8}\left(\mathrm{SCH}_{2} \mathrm{Ph}\right)_{12}\right]^{4-}$ have been isolated $[5,6,7], M=M o, W$. The structures consist of bridged arrangements of individual MoFe3S4(SR') 3 clusters. In III and in IV, the bridge is $\mathrm{M}\left(\mu_{2}-\mathrm{SEt}\right)_{3} \mathrm{Fe}\left(\mu_{2}-\mathrm{SEt}\right)_{3} \mathrm{M}$ (Fig. 1$)$ and $\mathrm{M}\left(\mu_{2}-\mathrm{SCH}_{2} \mathrm{Ph}\right)_{3} \mathrm{Fe}\left(\mu_{2}-\mathrm{SCH}_{2} \mathrm{Ph}\right)_{3} \mathrm{M}$, respectively. In I and II, the bridge is $\mathrm{M}$ (SEt) ${ }_{2} \mathrm{SM}$ and $\mathrm{Mo}(\mathrm{SEt})_{3} \mathrm{Mo}$, respectively.

The zero field M8ssbauer spectrum of (I) at 77 and $4.2 \mathrm{~K}$ consists of a single slightly asymmetric quadrupole doublet with broadened lines, with the magnitude of the quadrupole splitting and the line width increasing from 77 to $4.2 \mathrm{~K}$. Theoretical fits were made assuming one quadrupole pair with Lorentzian line shapes in each spectrum and the quadrupole splitting and isomer shifts are listed in Table $\mathrm{I}$. The zero field spectrum of II at 77 and $4.2 \mathrm{~K}$ consists of two partially resolved quadrupole doublets, with quadrupole splittings and line-widths increasing from 77 to $4.2 \mathrm{~K}$ for both doublets. The theoretical fits with unconstrained linewidths, intensities and positions indicated approximately 1:1 relative integrated intensities for the two doublets at both temperatures. At $77 \mathrm{~K}$, the doublet with larger splitting had slightly greater linewidths.

Mössbauer spectra of III and IV are similar to I and II, but have an additional component due to the $\mathrm{Fe}$ bridging atom (Fig. 2). In both cases, the additional component has an integrated intensity which is approximately $1 / 6$ that of the spectrum due to the cubane clusters, as expected from the structure. In III, the parameters are consistent with an assignment of low spin ferric for the bridging iron, while in IV, the parameters are consistent with high spin ferrous iron.
The spectral shapes indicate inequivalent iron sites in the clusters at low temperature, and some sensitivity of the cluster geometry to the nature of $R$ and $R^{\prime}$. However, isomex shifts and quadrupole splittings for iron atoms within the clusters are very similar, and are similar from cluster to cluster. The isomer shifts are observed to fall in the range $0.27-0.31 \mathrm{~mm} / \mathrm{sec}$ (relative to iron metal at the same temperature) and are nearly independent of $\mathrm{M}=\mathrm{Mo}$ or $\mathrm{W}$. Interpolation of the isomer shift with the nearly linear dependence of isomer shifts of tetrahedral $\mathrm{FeS}_{4}$ units on $\mathrm{Fe}$ formal oxidation state indicates a mean $\mathrm{Fe}^{+2.67}$ oxidation state in the $\left[\mathrm{MFe}_{3} \mathrm{~S}_{4}(\mathrm{SR})_{3}\right]$ clusters, equivalent to a formal $2 \mathrm{Fe}$ (III) $+\mathrm{Fe}$ (II) configuration. This result leads to the following formal Mo oxidation states: $\mathrm{Mo}(+3,+4)$ in $\mathrm{I}$ and $\mathrm{Mo}(+3,+3)$ in II, III and IV. However, one-electron reduction potentials are essentially independent of the formal oxidation state[6], indicating appreciable electron delocalization in the clusters in all four cases.

Spectra of $I$ in longitudinal magnetic fields at $4.2 \mathrm{~K}$ consist of a superposition of at least two subspectra with relative integrated intensities of approximately 1:2 (Fig. 3). The splitting of the lower intensity spectrum increases with increasing magnetic field, while the splitting of the higher intensity spectrum

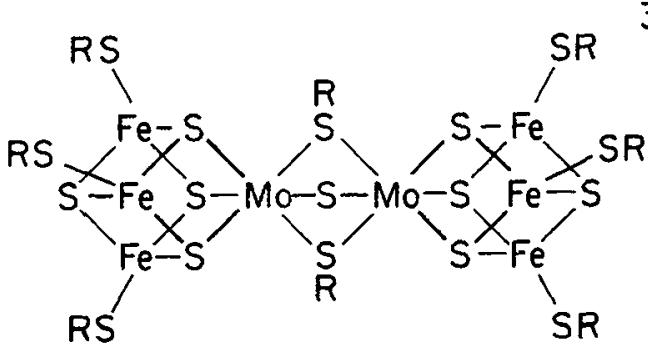

I 3-

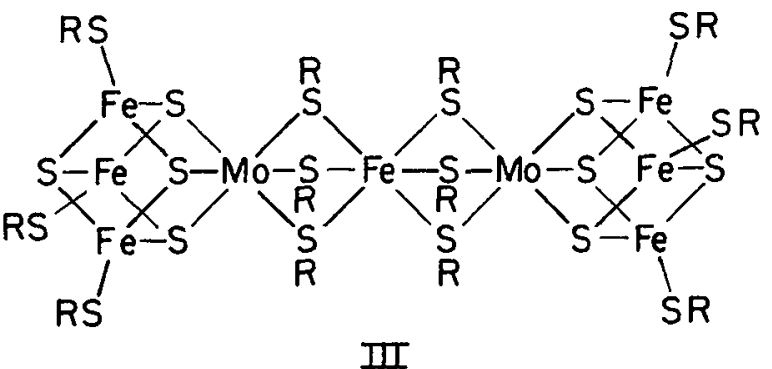

Fig. 1. Schematic drawings of structures I and III. 
decreases with increasing magnetic field, indicating opposite signs for the hyperfine interactions of the two subsites. $\left|\mathrm{H}_{\mathrm{hf}}\right|$ is 150 and 210 kOe for the less intense and more intense subsite, respectively. For both subspectra, the principal component of the electric field gradient tensor is negative and the asymmetry parameter is close to zero. Similar magnetic field spectra are obtained in II, III, and IV, except for slightly different overall splittings.

The observation of magnetic hyperfine structure induced by the external field means that the electronic ground state is paramagnetic and there is unpaired spin at all the iron atoms. Moreover, the two magnetic subsites with hyperfine interactions of opposite sign implies relatively weak spin coupling between clusters, and relatively strong antiparallel spin coupling within each cluster. This latter observation is consistent with the spin structures of $\left[\mathrm{Fe}_{4} \mathrm{~S}_{4}(\mathrm{SR})_{4}\right]^{3-}$ clusters, where antiparallel spin configurations are also observed. By analogy with those clusters, we would

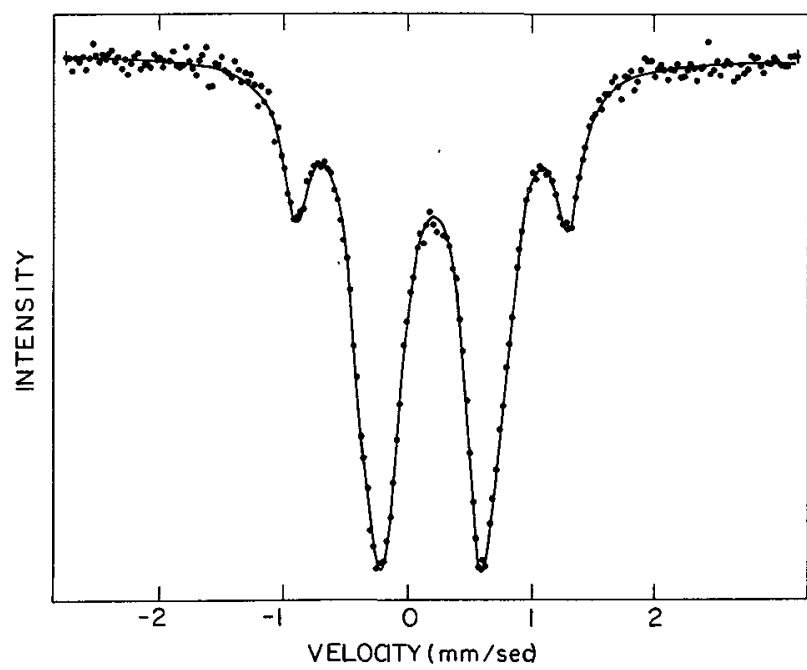

Fig. 2. Mössbauer spectrum of III at $77 \mathrm{~K}$.

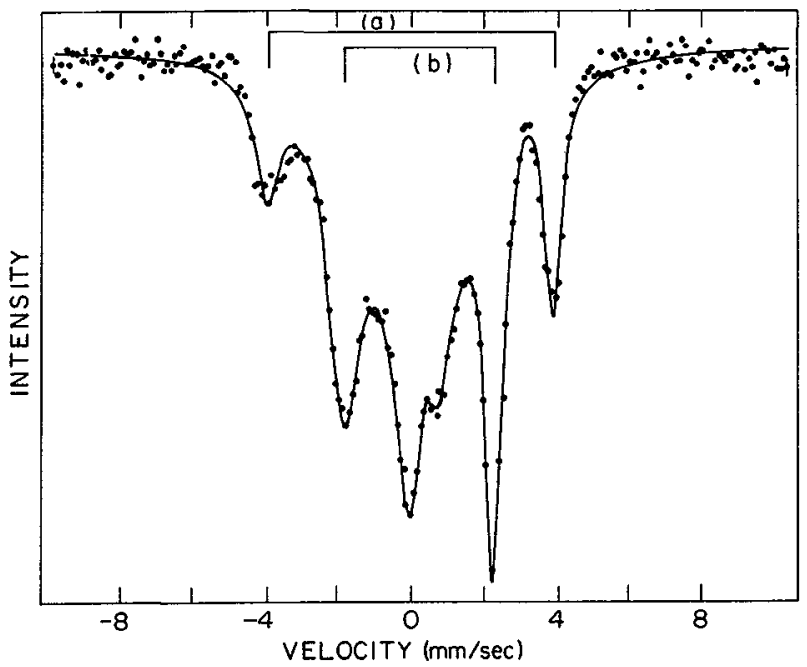

Fig. 3. Spectrum of $\mathrm{I}$ at $4.2 \mathrm{~K}, \mathrm{H}_{\mathrm{O}}=80 \mathrm{kOe}$. Splittings $a$ and $b$ increase and decrease with increasing $\mathrm{H}_{\mathrm{O}}$, respectively. expect the Mo spin to be coupled to the minority iron spin in each cluster, thus forcing the two Mo spins to be oriented parallel to each other at high fields.

The isomer shifts and quadrupole splittings for the clusters are comparable with the $T>40 \mathrm{~K}$ data obtained by Rawlings, et al. ${ }^{[8]}$. for the $M_{E P R}$ site in the FeMo cofactor and suggests a mean oxidation state near +2.67 for the iron atoms in the epr active level of that site.

Table I. Mössbauer Parameters at $77 \mathrm{~K}$

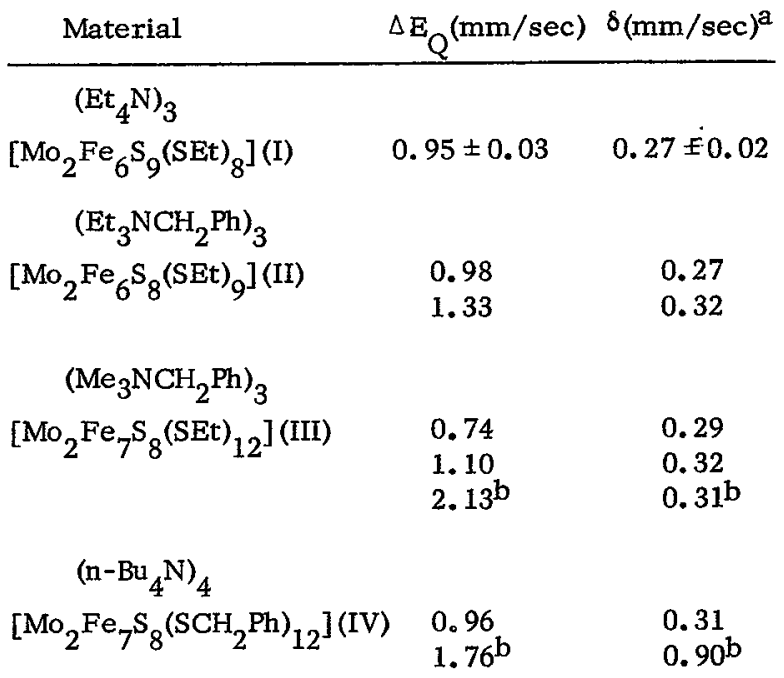

a Referenced to iron metal at $77 \mathrm{~K}$. b Bridge iron (relative intensity $\sim 1 / 7$ of total spectrum).

\section{REFERENCES}

* Supported by the National Science Foundation (USA)。

1. B. E. Smith and G. Lang, Biochem. J. 137, 169 (1974).

2. E. Milnck, H. Rhodes, W.H. Orme-Johnson, L.C. Davis, W.J. Brill and V.K. Shah, Biochim. Biophys. Acta 400, 32 (1975).

3. S.P. Cramer, W. O. Gillum, K.O. Hodgson, L.E. Mortenson, E. I. Stiefel, J.R. Chisnell, W.J. Brill, and V.K. Shah, J. Am. Chem. Soc. 100, 3814 (1978).

4. V.K. Shah and W. J. Brill, Proc. Nat. Acad. Sci. (USA) 74, 3249 (1977).

5. T.E. Wolff, J.M. Berg, C. Warnick, K. $\varnothing$. Hodgson, R. H. Holm and R. B. Frankel, J. Am. Chem. Soc. 100, 4632 (1978).

6. T.E. Wolff, $\overline{\text { J.M. }}$. Berg, P.P. Power, K.O. Hodgson, R. H. Holm and R.B. Frankel, J. Am. Chem. Soc. (in press).

7. T.E. Wolff, J.M. Berg, K.O. Hodgson, R.B. Frankel and R.H. Holm, J. Am. Chem. Soc. (in press).

8. J. Rawlings, V.K. Shah, J.R. Chisnell, W.J. Brill, R. Zimmerman, E. Münck and W.H. Orme-Johnson, J. Biol. Chem. 253, 1001 (1978). 